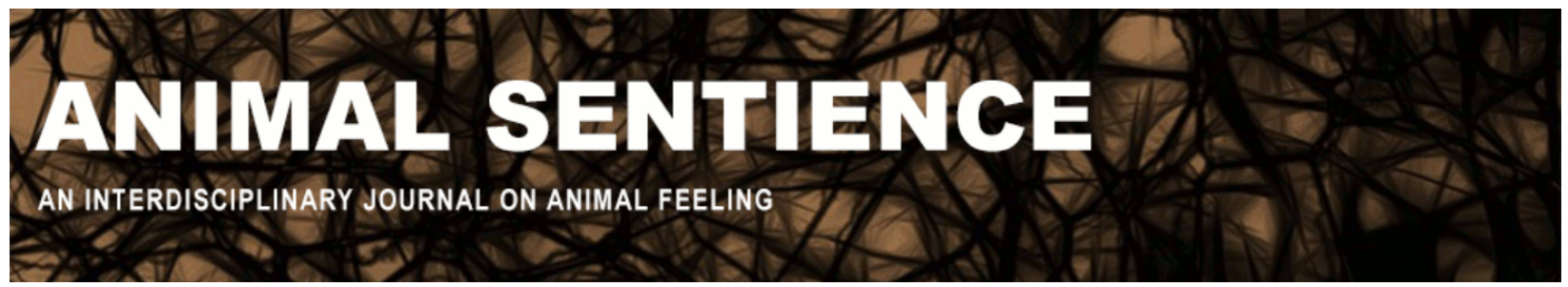

Gácsi, Márta (2017) Beyond the provable?. Animal Sentience 14(12)

DOI: $10.51291 / 2377-7478.1264$

Date of submission: 2017-11-24

Date of acceptance: 2017-12-02

(c) (i)

This article has appeared in the journal Animal

Sentience, a peer-reviewed journal on animal

cognition and feeling. It has been made open access,

free for all, by WellBeing International and deposited

in the WBI Studies Repository. For more information,

please contact

wbisr-info@wellbeingintl.org.

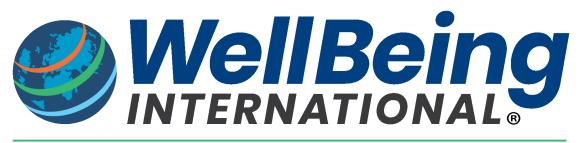

SOLUTIONS FOR PEOPLE, ANIMALS AND ENVIRONMENT 


\title{
Beyond the provable?
}

\author{
Commentary on Kujala on Canine Emotions
}

\section{Márta Gácsi \\ MTA-ELTE Comparative Ethology Research Group \\ Eötvös Loránd University}

\begin{abstract}
Reading Kujala's (2017) target article, I wondered whether we really need to approach the issue of animals' emotions the traditional way, asking whether animals have emotions that are identical, similar or precursors to those of humans. As an ethologist, I prefer to examine psychological phenomena from an evolutionary perspective, focusing on Tinbergen's (1963) four questions (Bateson \& Laland 2013).
\end{abstract}

Márta Gácsi is senior researcher at the
Comparative Ethology Research Group of the
Hungarian Academy of Sciences and investigates
different aspects of dog-human interaction in the
Family Dog Project. Her research includes wolf-dog
comparative studies, ethorobotics, and the
neurobiological background of dogs socio-
cognitive and emotion processing abilities.
etologia.elte.hu/en/cv-marta-gacsi-phd/

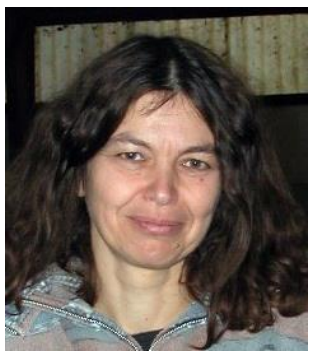

One might claim that the emergence of expressions of inner states/emotions during evolution is self-evident in contexts when honest signals are adaptive. Yet we can never know whether and how animals feel emotions; this might not even fall into the category of processes that can be studied by science. In an increasing number of species we can nevertheless collect behavioural and physiological data that can be connected to emotional situations or to the processing of inner states of social partners (see Andics et al. 2016, Kis et al. 2017, for the case of dogs). Whether we can extend this to non-human animals depends only on how broadly we define emotion. I do not blame Kujala (2017) for not providing a proper definition early on. Coming up with one that would fit into the theoretical framework of all related fields would have been a huge challenge.

Should we compare them to ourselves? We would like to compare advanced functions in nonhuman animals to our own, partly to learn how we evolved into the only species able to write papers on the welfare of other species, partly because learning more about animals' inner states, emotions, intentions, and ability to suffer may help us decide how to treat them. To reach these goals we need to argue within the theoretical framework of one of the relevant disciplines (biology, psychology, philosophy, etc.); it is too early to try combining them all. 
Ethologically basic emotions. Some 40 to 50 years ago, it was already self-evident that the most popular model species, the mouse, does have at least one emotion: fear (e.g., Blanchard and Blanchard 1969). Aggression - referring to aggressive behaviours rather than anger - was also widely investigated in mice (e.g., Svare and Gandelman 1973). In the case of both fear and aggression, all four categories of Tinbergen's (1963) criteria (phylogeny, adaptive value, mechanism, and ontogeny) had been extensively studied in appropriate experimental environments.

Among positive emotions, although satiation (contentment?) may not be an emotion, social play can be associated with enjoyment, so the inner state in social play may be closely related to the human notion of happiness (e.g., Garvey 1990).

Our oldest and special friend. The non-human species about whose cognitive abilities, social behaviour, and emotions we know the most is the domestic dog (e.g., Pongrácz et al. 2006, Faragó et al. 2014a), although biologists cannot even reach a consensus on its taxonomic name. In the USA and Australia, it is called Canis lupus familiaris (because of the minimal genetic differences from the wolf); in most of Europe, it is called Canis familiaris (because of the huge ecological and behavioural differences from the wolf). Both sets of researchers insist on using their taxon in their publications and passively accept the other label in the papers of others. This would be a minor issue if we did not know that dogs, unlike wolves, are attached to their owners (Topál et al. 2005). This unique interspecific social bond has been shown to be functionally similar to the human infant-mother attachment bond (Topál et al. 1998); it is not to be confused with social attraction. Since our dogs are dependent on us and we provide a secure base (Horn et al. 2013), a safe haven (Gácsi et al. 2013) and social reference (Merola et al. 2012) for them, it is a major concern whether they need to be treated with specific care. Attachment is not an emotion, however, but a testable behavioural system; in relevant situations dogs show typical responses to the absence and presence of their owners. Labelling these responses (separation) anxiety rather than sadness or fear, and greeting behaviours rather than happiness, seems scientifically sound. However, we might end up in the same situation as in the case of animal personality, a trait that was formerly reserved for humans, but we now recognize in animals (Gosling 2001).

Secondary emotions - putting words in quotations helps? According to most definitions, secondary emotions require more processing and arise from beliefs or expectations related to other/primary emotions (Evans 2001). These pose a challenge for testing in animals. However, it can help if we adopt a functional approach and consider the adaptive value of the behaviours that are functionally similar to human ones. We can study the phylogenetic roots of complex human emotions such as empathy in animals (Preston \& De Waal 2002); already in the 60s, researchers had demonstrated "empathy-like" behaviour in rats (Rice \& Gainer 1962). In dogs, jealousy seems a clear case; defending a possession, a bone, a mate, or another valuable social partner (owner) may well belong to the very same, relatively simple biological system.

Owners seem to be able to differentiate guilty and non-guilty greeting behaviours in their dogs, but dogs also tend to show guilty behaviours if they face a temptation but can resist it (Hecht et al. 2012). Yet guilty behaviour cannot be proof of a high socio-cognitive capacity. Even in humans, guilt is strongly connected to culture; we all learn the specific rules of our 
smaller and larger social groups during development, and we either behave accordingly, or show signs of guilt. Some of us may even feel guilty. But we all learn how and why to express guilt because it is adaptive.

Attributed emotions? Based on 20 years of data from our basic questionnaire at the Family Dog Project, Budapest, some dog owners take a stance on considering their pet dogs as family members/children, whereas others claim that dogs are no different from other useful domestic species - although the proportion of the two extremes keeps changing.

In the traditional approach, which is still alive, dog-human relationships are thought to be based on the rules of a wolf pack: in dog-human mixed packs, the owner must act as an alpha wolf. In contrast, some researchers (and many owners) have adopted an anthropomorphic approach and attribute human-like roles and capacities to the dog. Pet dogs live in a social world similar to that of human infants; some experiments have revealed close similarities between dogs and infants. Hence viewing pet dogs as children also has some basis. It has recently been suggested that the modern human-pet dog bond is more like a friendship that may include asymmetry, such as dominant-subordinate or caregiver-receiver roles in the relationship (Miklósi 2014). The fact that owners attribute human-like emotions to their dogs is accordingly not surprising; it cannot be considered just unscientific anthropomorphism but is rather a phenomenon worth studying (Konok et al. 2015).

Robotic emotions. Functional behavioural parallels between dogs and humans suggest a trend for convergent evolution; thus, the dog has been widely used as a natural model for studying some aspects of the evolution of human socio-cognitive behaviour. The similar function of assistance dogs and service robots or pet dogs and companion robots, also makes dogs a promising model for developing social robots (Miklósi et al. 2017). Questionnaire data have revealed that the most preferred features of our dogs are connected to their emotions (toward us); so, we should try to use the features of dogs' basic emotional behaviours to design more lovable (acceptable) social robots (Konok et al. 2017). Human-like social skills in robots are still far away, so it might be more useful to view robots as a new species. The main advantage of building canine social behaviour into companion robots is that it is relatively simple, so it may be more easily implementable technically (Lakatos et al. 2014). Recent data suggest that people can understand the emotional expressions of a robot if its behaviour was inspired by dog behaviour (Faragó et al. 2014b), and tend to accept a service robot more readily if, in emotionladen situations, it shows responses borrowed from dog behaviour (Gácsi et al. 2013b).

Each doing our share. The task of biologists is to collect sound data, observe, measure, and analyse the behaviours and physiological changes in animals in relevant contexts. Psychologists and philosophers can provide deeper insights into human-specific features and can integrate cultural and moral aspects of emotional processing. Sizing up, making decisions, and bearing the consequences - that's for all of us to do. 


\section{References}

Andics, A., Gábor, A., Gácsi, M., Faragó, T., Szabó, D., Miklósi, Á. (2016). Neural mechanisms for lexical processing in dogs. Science 353: 1030-1032. doi: 10.1126/science.aaf3777

Bateson, P., Laland, K.N. (2013). Tinbergen's four questions: An appreciation and an update. Trends in Ecology \& Evolution 28: 712-718,

Blanchard, R.J., Blanchard, D.C. (1969). Crouching as an index of fear. Journal of Comparative and Physiological Psychology 67: 370-375.

Evans, D. (2001). Emotion: The science of sentiment (New York: Oxford University Press), 5-6.

Faragó, T., Andics, A., Devecseri, V., Kis, A., Gácsi, M., Miklósi, Á. (2014a). Humans rely on the same rules to assess emotional valence and intensity in conspecific and dog vocalizations. Biology Letters 10: 20130926.

Faragó, T., Miklósi, Á., Korcsok, B., Száraz, J., Gácsi, M. (2014b). Social behaviours in dog-owner interactions can serve as a model for designing social robots. Interaction Studies 15: 143172.

Gácsi, M., Kis, A., Faragó, T., Janiak, M., Muszyński, R., Miklósi, Á. (2016). Humans attribute emotions to a robot that shows simple behavioural patterns borrowed from dog behaviour. Computers in Human Behavior 59: 411-419.

Gácsi, M., Maros, K., Sernkvist, S., Faragó, T., Miklósi, Á. (2013a). Human analogue safe haven effect of the owner: Behavioural and heart rate response to stressful social stimuli in dogs. PLOS ONE 8: e58475.

Gácsi, M., Szakadát, S., Miklósi, Á. (2013b). Assistance dogs provide a useful behavioral model to enrich communicative skills of assistance robots. Frontiers in Psychology 4: 971.

Garvey, C. (1990). Play. Cambridge, MA: Harvard University Press.

Gosling, S. D. (2001). From mice to men: What can we learn about personality from animal research? Psychology Bulletin 127: 45-86.

Hecht, J., Miklósi, Á., Gácsi, M. (2012). Behavioral assessment and owner perceptions of behaviors associated with guilt in dogs. Applied Animal Behaviour Science 139: 134-142.

Horn, L., Huber, L., Range, F. (2013). The importance of the secure base effect for domestic dogs - Evidence from a manipulative problem-solving task. PLOS ONE 8(5): e65296.

Kis, A., Hernádi, A., Miklósi, B., Kanizsár, O., Topál. J. (2017). The way dogs (Canis familiaris) look at human emotional faces is modulated by oxytocin. An eye-tracking study. Frontiers in Behavioral Neuroscience, doi: 10.3389/fnbeh.2017.00210

Kis, A., Kemerle, K., Hernádi, A., Topál, J. (2013). Oxytocin and social pretreatment have similar effects on processing of negative emotional faces in healthy adult males. Frontiers in Psychology 4: 532.

Konok, V., Korcsok, B., Miklósi, Á., Gácsi, M. (2017). Should we love robots? - The most liked qualities of companion dogs and how they can be implemented in social robots. Computers in Human Behavior 80: 132-142. doi: 10.1016/j.chb.2017.11.002

Konok, V., Nagy, K., Miklósi, Á. (2015). How do humans represent the emotions of dogs? The resemblance between the human representation of the canine and the human affective space. Applied Animal Behaviour Science 162: 37-46.

Kujala, M. V. (2017). Canine emotions as seen through human social cognition. Animal Sentience 14(1). 
Lakatos, G., Gácsi, M., Konok, V., Brúder, I., Bereczky, B., Korondi, P., Miklósi, Á. (2014). Emotion attribution to a non-humanoid robot in different social situations. PLOS ONE 9: e114207.

Merola I, Prado Previde, E., Marshall-Pescini, S. (2012). Dogs' social referencing towards owners and strangers. PLOS ONE 7(10): e47653.

Miklósi Á. (2014). Dog behaviour, evolution, and cognition. Oxford, UK: Oxford University Press.

Miklósi, Á., Korondi, P., Matellán, V., Gácsi, M. (2017). Ethorobotics: A new approach to humanrobot relationship. Frontiers in Psychology, doi: 10.3389/fpsyg.2017.00958

Pongrácz, P., Molnár, C., Miklósi, Á. (2006). Acoustic parameters of dog barks carry emotional information for humans. Applied Animal Behaviour Science 100: 228-240.

Preston, S. D., de Waal, F. B. M. (2002). Empathy: Its ultimate and proximate bases. Behavioural Brain Sciences 25: 1-72.

Rice, G. E. J., Gainer, P. (1962). "Altruism" in the albino rat. Journal of Comparative \& Physiological Psychology 55: 123-125.

Svare, B., Gandelman, R. (1973). Postpartum aggression in mice: Experiential and environmental factors. Hormones and Behavior 4: 323-324.

Tinbergen, N. (1963). On aims and methods of ethology. Ethology 20(4): 410-433.

Topál, J., Gácsi, M., Miklósi, Á., Virányi, Z., Kubinyi, E., Csányi, V. (2005). Attachment to humans: A comparative study on hand-reared wolves and differently socialized dog puppies. Animal Behaviour, 70: 1367-1375.

Topál, J., Miklósi, Á., Csányi, V. (1998). Attachment behaviour in dogs: A new application of Ainsworth's (1969) Strange Situation Test. Journal of Comparative Psychology 112: 219-229. 